\title{
PASSIVE ADAPTIVE STRATEGIES FOR THE OPTIMISATION OF COMFORT AND ENERGY DEMAND IN TRADITIONAL AND CONTEMPORARY BUILDINGS IN HOT, HUMID CLIMATES
}

\author{
UDO DIETRICH \& LAURA GARCIA RIOS \\ REAP Research Group (Resource Efficiency in Architecture and Planning), \\ HafenCity University Hamburg, Germany
}

\begin{abstract}
Salvador, Brazil was chosen as the location for a hot and humid climate. Temperatures lay in the range between 25 and $32^{\circ} \mathrm{C}$ in the hot period (around December) and 22 and $27^{\circ} \mathrm{C}$ in the cooler one (around June). An assessment of the outdoor temperatures with adaptive comfort model EN 15251 shows that with only natural ventilation there are good chances to reach comfort. Overheating may arise from internal use, artificial light and solar heat transfer through windows as well as through opaque walls and roofs (exterior surfaces absorb solar radiation, construction heats up and the high-temperature transfers remarkably through the construction to the interior). Representative local traditional and contemporary buildings were selected and analysed with transient thermal simulation. Results show that the heat transfer through the constructions is in case of overheating the dominant component. In both buildings, the last floor under the roof overheats. Only with an improvement of the construction (by adding layers that contribute to thermal insulation) comfort can be reached. The intermediate floor in the traditional building with thick adobe walls $(60 \mathrm{~cm})$ behaves very well, while the contemporary building with thin concrete walls $(10 \mathrm{~cm})$ overheats. Comfort can be reached only by bringing the wall into shadow (cladding) or optimizing the construction by adding insulation or replacing concrete with hollow bricks, increased natural (shaft) ventilation and shading of the windows. Positively it has to be said that, in the local contemporary architecture itself with building shape, (moderate) size and placement of windows, shading system, cross ventilation is not a fundamental obstacle to reach comfort. In other countries, the trend to bigger windows leads without $\mathrm{AC}$ in any case already to discomfort. But the tendency to construct cost-optimized, to use "modern" materials like concrete (without protecting cladding or insulation) and the hope that users will install AC has led to non-optimal constructions. Detailed recommendations for the improvement of roof and wall constructions are given in the paper. Keywords: hot and humid climate, adaptive comfort model, natural ventilation, heat transfer through constructions, transient thermal simulation, traditional architecture, contemporary architecture.
\end{abstract}

\section{INTRODUCTION}

Salvador is located in the tropical zone, at 13 degrees' south latitude and 38.5 degrees' longitudes west. The city has a high solar incidence all year, precipitation ranging from $1800 \mathrm{~mm}$ to $2000 \mathrm{~mm}$ per year, in average maximum and minimum temperatures of $29^{\circ} \mathrm{C}$ and $22^{\circ} \mathrm{C}$ respectively, relatively high humidity around $80 \%$ the whole year. The favourable winds are mainly the southeast winds; with less intensity from the south and the northeast. The city of Salvador had the oldest urban Brazilian agglomeration which was the main location of the colonial government of Portugal (1529-1763). Currently, the population is about 3 million [1].

The traditional Portuguese architecture in Salvador until the end of the 19th century was well adapted to the climate of the city. Narrow houses were common, single or two-story houses with doors and windows facing the street and the backyard, with a corridor that goes from the front to the back, which facilitates the air circulation (see Fig. 1). The houses feature a high ridge, reaching up to double the height of the lowest part (3.00 to $3.50 \mathrm{~m}$ ). 


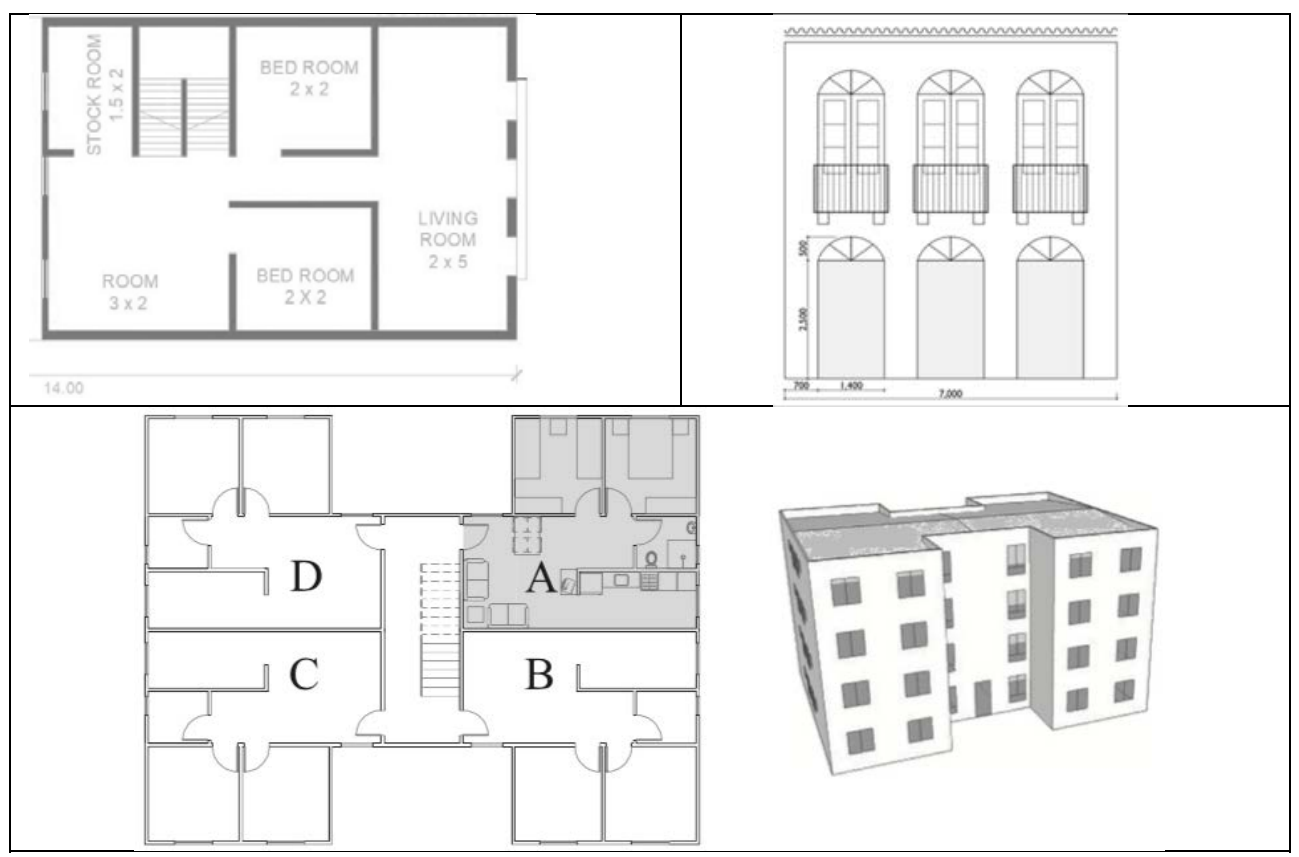

Figure 1: Prototype traditional (top) and contemporary (bottom) building in Salvador, Brazil with floor plan and front façade.

Usually, both façades (front and back) have windows and doors with an upper window. The windows were elevated from the street level to guarantee privacy and were always open to allow natural ventilation. Many of them have an internal skylight for lighting and ventilation (air drawn) from the inner rooms near the top of the roof.

Wall materials are made of massive bricks, adobe, rammed earth and sometimes stones, presenting a greater resistance against humidity. The houses usually have a wood structure that gives stability to the structure and absorbs the roof and upper deck load, the thickness can vary from $0.3 \mathrm{~m}$ to $1.2 \mathrm{~m}$. The gable roofs are made of ceramic tiles.

The orientation is very varied; however, the most common and desired is to the east. Due to Salvador has excellent ventilation during the whole year and good shade temperature, it is not essential to use an air condition system when an architectural solution is possible: High ceilings and cross ventilation.

Comparing contemporary architecture with traditional due to the higher urban density presented high-raised buildings with an average of 5 storeys (see Fig. 1). The main wall materials are concrete or ceramic, supplemented by canopies and porches. Doors and windows are used for ventilation.

\section{METHODS OF ASSESSMENT OF CLIMATE, COMFORT AND CONSTRUCTIONS: FIRST CONCLUSIONS FOR PASSIVE OPTIMIZED BUILDINGS}

\subsection{Assessment of comfort}

Residential buildings are in general naturally ventilated (even if AC is used). That's why thermal comfort can be assessed according to adaptive comfort model EN 15251 [2]. Here, 
comfort category II should be fulfilled by new (contemporary) buildings and category III by existing (traditional) ones. To avoid too strong assessments a limited number of exceedances is allowed by the standard, recommended are in maximum $3 \%$ of the hours of usage.

\subsection{Assessment of climate}

Outdoor temperatures in Salvador are widely in range of comfort category II (see Fig. 2). An assessment of outdoor temperatures with EN 15251 ends with comfort category III and $0.5 \%$ of exceedance; category II is reached with slightly more than the threshold of $3 \%$ of exceedance.

Blue is the outdoor temperature, assumed also as operative indoor temperature. The more horizontal lines mark the corridors for comfort category I (orange), II (red) and III (dark blue).

Like it is defined by the standard, the comfort corridors swing smoothly with the daily mean value of the outdoor temperature. Comfort category II (red line) is very seldom exceeded in Salvador, Brazil. The comfort corridors show also the range of as comfortable perceived indoor temperatures; for category II it lays in the hot period between 26 and $31^{\circ} \mathrm{C}$, in the cooler one between 25 and $30^{\circ} \mathrm{C}$.

That delivers a first hint that comfort could be reached by using natural ventilation to remove to high heat gains. The corresponding architecture should be based on two concepts:

First, avoid too high heat gains:

- For transparent areas: Moderate window area, good shading system

- For opaque constructions: TAD and U-value in sufficient quality (see Chapter 2.3)

- For internal heat gains: Energy saving equipment.

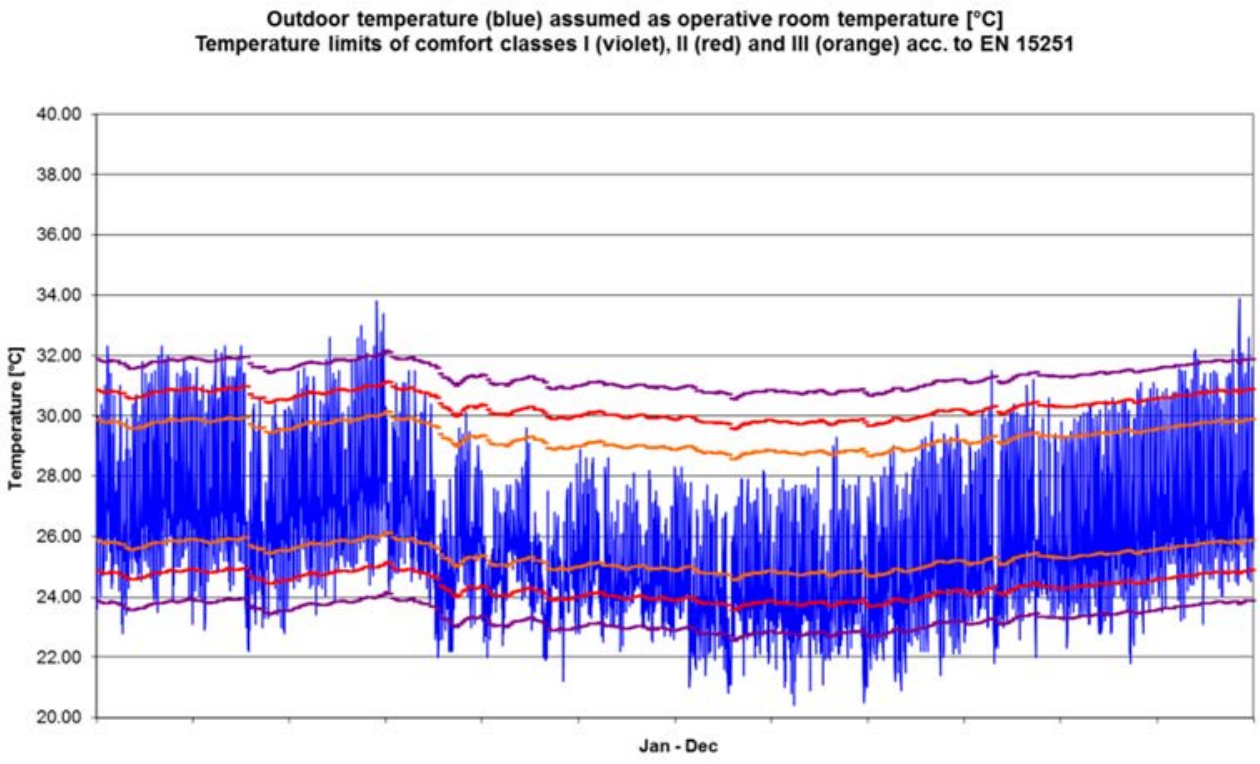

Figure 2: Assessment of outdoor temperatures with EN 15251. 
Second, remove too high heat gains by natural ventilation:

- Openings for ventilation big enough, correct placed and easy to control

- Possibility for night ventilation in connection with a moderate to heavy construction to store cool night temperatures in the building

- In minimum cross ventilation (ventilation openings in opposite façades, no obstacles in the interior of the apartments) better ventilation with height difference / shafts.

Furthermore, Salvador is located a bit south of the equator. That leads to a very high solar radiation and because of small differences in global horizontal radiation to smooth seasons, a hot season around December and a cooler season around June. Very special is the position of the sun in the sky during these seasons. Because of the ecliptic the sun is in December still in the southern part of sky (at quite high angles) and in the cooler season on the northern one (Fig. 3). That means that south façades need special protection against sun in the hot season while north façades can well receive solar heat gains in the cool one.

Because of the high position of the sun in the sky are especially roofs strong charged by solar radiation the whole day long. The construction of roofs shall hinder that absorbed solar radiation can pass strong and quick into the interior of buildings. Façades are affected by the sun less strongly and only during a limited number of hours during a day. But nevertheless also façades shall be constructed in a way that they avoid a strong and quick transfer of absorbed solar radiation.

\subsection{Assessment of constructions}

In cold and moderate climates, the most important quantity of a construction is the U-value. It describes how good the temperature difference between indoor and outdoor can be kept and how heat losses are reduced. In hot climates the temperature difference is much less and thus much less important. Decisive is here more the dynamical behaviour of a construction if solar radiation strikes on the external surface. The temperature-amplitude-damping (TAD) is the ratio between the amplitude in temperature on the exterior surface to the resulting one on the interior surface; thus it describes how strong the temperature transfer from the exterior surface to the interior is reduced (damped). For the calculation the standard EN ISO 13786

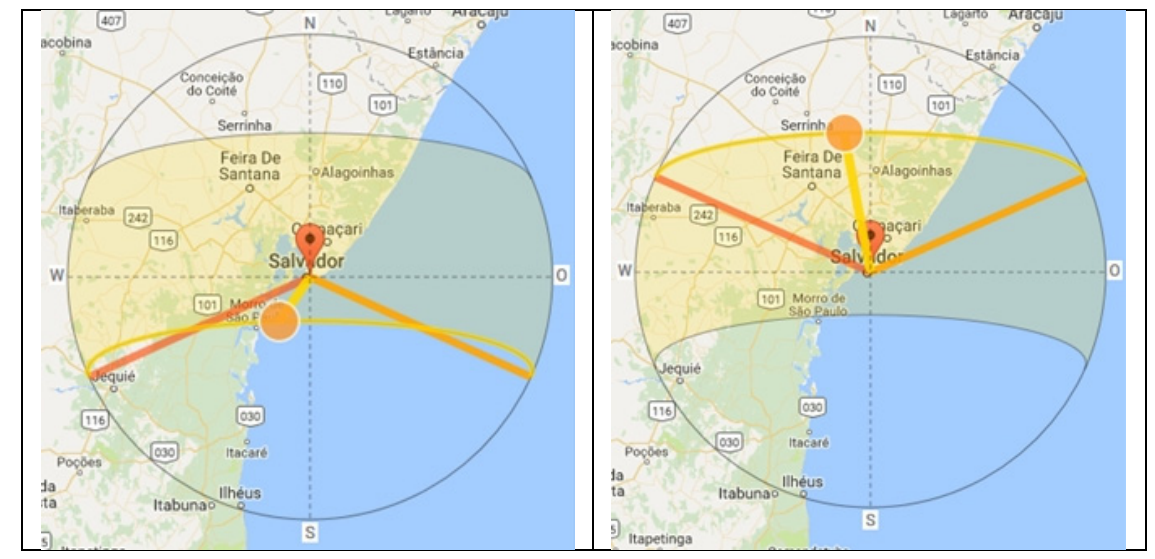

Figure 3: Sun position in Salvador in December (left, sun is in south!) and in June (right, sun is in north) [3]. 
[4] can be used, (EN ISO 13786 calculates only the decrement. To get TAD decrement has to be multiplied with the ratio $(\mathrm{Ti}-\mathrm{Te}) /(\mathrm{Tsi}-\mathrm{Ti})$, calculated under stationary conditions (like for a U-value calculation); Tsi is the temperature at the interior surface.)

In literature are also very good approximate formulas [5]. Recommended values for TAD are bigger than 10, excellent values are bigger than 20 . Values under 5 are very critical; the construction (if in sun) would transfer a lot of heat and overheat the building.

The chosen prototypical examples for contemporary and traditional buildings show a wide range of TAD from critical to excellent and thus demonstrating possibilities of architectural practice (see Table 1).

Besides the solar heat transfer construction should have a good behaviour to store cool temperatures from night air, which means that they should store as quick as possible and as much as possible. The best material here is concrete. However, Table 1 shows that concrete alone as external wall fails if it is in sun.

Further rules for passive optimized buildings can be derived:

- Heavy materials as thermal storage should be realized with internal constructions that are not in sun.

- External constructions can have internal layers with heavy materials but they have to be protected against solar heat transfer by shadowing the construction with a cladding / roof or adding externally a layer of thermal insulation, in minimum 3 to $4 \mathrm{~cm}$.

Alternatively, external constructions can combine both quantities with the choice of massive but lighter material in a sufficient thickness (hollow bricks, in minimum $24 \mathrm{~cm}$ ) or also be a light construction with in minimum $6 \mathrm{~cm}$ insulation (and the interior constructions are heavy and act as thermal storage).

Table 1: List of constructions in contemporary and traditional prototypical buildings with temperature-amplitude-damping (TAD) and assessment for the risk of solar heat transfer. In the second column $\mathrm{C}$ stands for contemporary, i it's improvements and $\mathrm{T}$ for traditional.

\begin{tabular}{|c|c|c|c|}
\hline Description & & TAD $[-]$ & Assessment \\
\hline $\begin{array}{l}\text { Roof, } 10 \mathrm{~cm} \text { light concrete with tiles } \\
\text { (assessed with } \mathrm{R}=0.4 \mathrm{~m}^{2} \mathrm{~K} / \mathrm{W} \text { ) }\end{array}$ & $\mathrm{C}$ & 10.8 & $\begin{array}{l}\text { Still critical for a roof, solar } \\
\text { heat transfer is remarkable, } \\
\text { see Section } 3 \text {. }\end{array}$ \\
\hline $\begin{array}{l}\text { - Improved with } 2 \mathrm{~cm} \text { thermal } \\
\text { insulation }\end{array}$ & $\mathrm{C}, \mathrm{i}$ & 18.4 & $\begin{array}{l}\text { Nearly good, but solar heat } \\
\text { transfer still notable. }\end{array}$ \\
\hline $\begin{array}{l}\text { - Further improved with } 6 \mathrm{~cm} \\
\text { thermal insulation }\end{array}$ & $\mathrm{C}, \mathrm{i}$ & $>=30$ & Good. \\
\hline $\begin{array}{l}\text { Roof, } 2.54 \mathrm{~cm} \text { of wood with tiles } \\
\text { (assessed with } \mathrm{R}=0.4 \mathrm{~m}^{2} \mathrm{~K} / \mathrm{W} \text { ) }\end{array}$ & $\mathrm{T}$ & 7.8 & $\begin{array}{l}\text { Critical for a roof, solar heat } \\
\text { transfer is remarkable, see } \\
\text { Section } 3 \text {. }\end{array}$ \\
\hline Wall $10 \mathrm{~cm}$ concrete & $\mathrm{C}$ & 2.1 & $\begin{array}{l}\text { Extremely critical, due to the } \\
\text { strong solar heat transfer. }\end{array}$ \\
\hline - Improved with $4 \mathrm{~cm}$ insulation & $\mathrm{C}, \mathrm{i}$ & 13.6 & Good. \\
\hline Wall hollow bricks $24 \mathrm{~cm}$ & $\mathrm{C}, \mathrm{i}$ & 13.5 & Good. \\
\hline Light wall $6 \mathrm{~cm}$ insulation & $\mathrm{C}, \mathrm{i}$ & $>=15$ & Good. \\
\hline Wall $56 \mathrm{~cm}$ adobe, $2 \times 2 \mathrm{~cm}$ plaster & $\mathrm{T}$ & $>=100$ & $\begin{array}{l}\text { Excellent. No solar heat } \\
\text { transfer. }\end{array}$ \\
\hline
\end{tabular}




\section{TRANSIENT SIMULATION OF THERMAL COMFORT: COMPARISON OF TRADITIONAL AND CONTEMPORARY ARCHITECTURE}

\subsection{General assumptions and findings}

Based on literature studies, prototypes of traditional [6] and contemporary [7] residential buildings in Salvador were defined (see Fig. 1 and Chapter 3.2 and 3.3) and were modelled in Primero Comfort [8]. Both buildings have a quite moderate window to wall ratio of $26 \%$ (traditional) and $15 \%$ (contemporary), a first precondition for an optimized building is fulfilled. On the other hand, the windows have to be big enough for the view out of the window and daylight access what is given in both prototypes. For that reason, the window size was not investigated by the simulations and taken as a constant.

The traditional building was clearly constructed to allow cross ventilation, on top of the windows are separate operable openings; they are located in two opposite façades in short distance to foster cross ventilation.

The contemporary building has four units in one floor, one in each corner and thus no opposite façades for cross ventilation. Windows have sashes to allow big operable areas for ventilation. Nevertheless, a kind of (reduced) cross ventilation is possible only over windows in the diagonal of the apartment. Although the floor plan would allow it in principle, there are no ventilation shafts in the building for higher natural ventilation foreseen.

In previous simulations, different shading systems were investigated. Overhangs were found as less effective. That is not a big surprise because of the high sun position. The main contribution in solar radiation onto the windows comes from the bright sky and is not influenced by overhangs. External shading systems like louvres were obviously not foreseen neither in traditional nor in contemporary architecture. But shading in the sense of a screen / mesh could be easily installed by the users. It would reduce solar radiation into the room but (with intelligent design, see Arabic Mashrabiyas) remain the view out of the window. It was found out that up to an opaque part of the mesh of $60 \%$ there is still enough daylight in the rooms and no supplementary need for artificial light. Such a shading system was used in the simulations to assess the impact on thermal comfort without a reduction in visual comfort.

Simulations showed that east and west oriented façades receive most insolation because of the small angle of elevation of the sun, followed by south oriented ones (in the hot season sun is in the south, see Section 2.2). For that reason, always the apartment with the worst conditions was chosen for simulation, all others will behave better. Simulations were always assessed with EN 15251 and comfort category II with a threshold of 3\% of exceedances. The traditional building could be assessed more fairly also with comfort category III for existing buildings, as rule of thumb can be assumed that it is reached if the number of exceedances in comfort category II is at about $10 \%$. For both buildings cross ventilation simulation was assumed; knowing that it is only limited possible in the contemporary building. But with this assumption results could be directly compared, differences arise only out of different constructions and materials. The infiltration is set to $0.351 / \mathrm{h}$, ventilation to $21 / \mathrm{h}$ between 6 am and $10 \mathrm{pm}$ and because of the higher temperature difference indoor-outdoor to $31 / \mathrm{h}$ between $20 \mathrm{pm}$ and $6 \mathrm{am}$.

\subsection{Traditional architecture}

Simulated was the east-west oriented apartment (Fig. 4) in the upper floor as worst case. Investigated were two different situations, the apartment like it is with the roof as external construction and the same apartment as a (fictive) intermediate floor with an internal ceiling. 


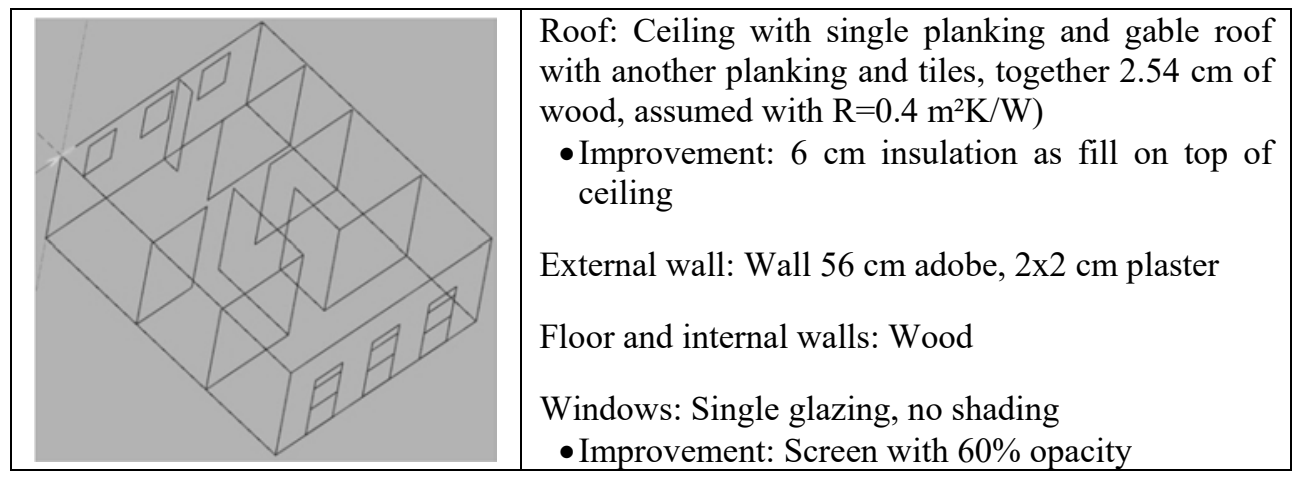

Figure 4: Chosen traditional prototypical building and simulated constructions.

The simulation of the apartment in the last floor (under the roof) ends with $37 \%$ of exceedances above comfort category II (with N-S orientation $27 \%$ ); thus far from comfort! The roof behaves not well, however, the walls behave excellent; thus a concentration on an improvement of the roof is the best measure. A traditional building is already erected and improvements are not always possible such as for new buildings. But to add simply a fill on top of the ceiling under the roof and a screen to the windows should easily be possible. With these measures $(6 \mathrm{~cm}$ thermal insulation assumed for the roof) $9 \%$ of exceedance of comfort category II and $2 \%$ in category III are reached - acceptable for existing buildings.

The simulation of the intermediate floor (with internal ceiling) shows excellent results, it reaches $15 \%$ exceedance of comfort category II and $2 \%$ in category III. With a screen $(60 \%)$ on the windows exceedance reduces to 6 (cat. II) and $0 \%$ (cat. III) resp. For north-south orientation the apartment is always without screen in category II.

\subsection{Contemporary architecture}

Simulated was the apartment with the worst conditions (see Fig. 5), which is the one in the $\mathrm{N}-\mathrm{E}$ corner (marked with $\mathrm{A}$ in Fig. 1). Investigated were two different situations, the apartment like it is with the roof as external construction and the same apartment as a (fictive) intermediate floor with an internal ceiling.

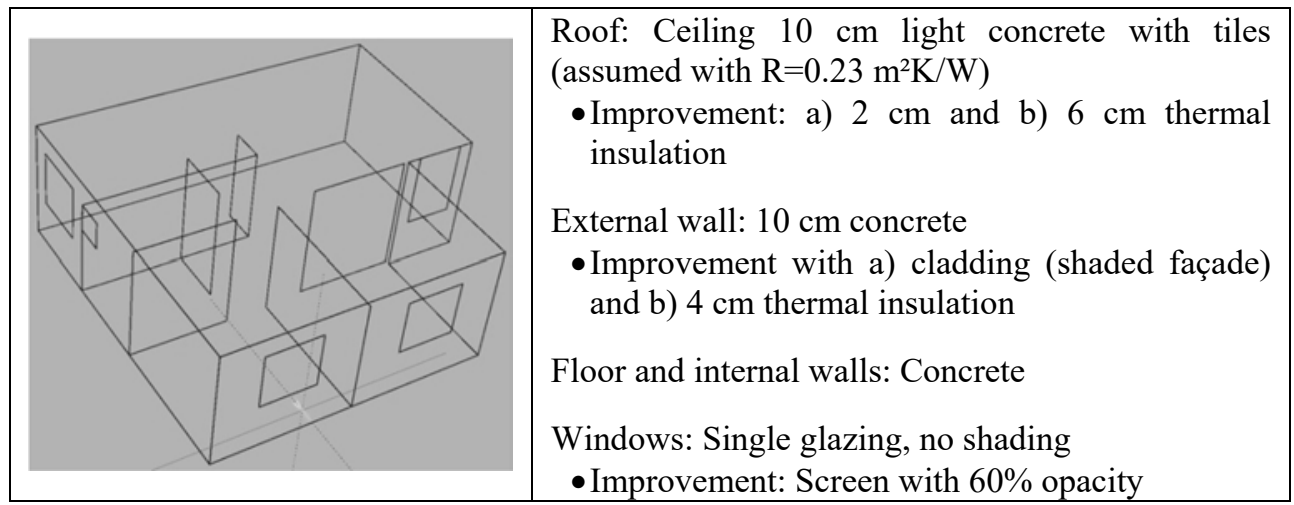

Figure 5: Chosen contemporary prototypical building and simulated constructions. 
The red areas show the upper limits of comfort categories I, II and III. The simulated indoor temperature and the corresponding daily mean of the outdoor temperature form one black point for each hour of usage. The graph shows the apartment like it is in reality, $32 \%$ of exceedance above comfort category II - far from comfort especially on the hot and sunny days (around December).

The simulation of the apartment in the last floor (under the roof) ends with $32 \%$ of exceedances above comfort category II; thus far from comfort (see Fig. 6).

The initial situation with the apartment like it is in reality shows that there are plenty hours of usage (black points in Fig. 6) very near above and also below the limit of comfort category II.

One can say that the apartment is in a very critical, sensible range where small changes in construction, shading, ventilation use etc. can cause remarkable differences in comfort. If most of the points would be below the comfort limit the apartment would be in a more insensible condition and would be in the comfort assessment much more robust against changes.

To improve comfort in a new building it was assumed that it would be possible to include vertical ventilation shafts; the increased air change rate is simulated with $4 \mathrm{l} / \mathrm{h}$.

The different measures of improvement were simulated. Table 2 shows possible successful improvements (target of only $3 \%$ of exceedance of comfort category II is reached). Further variants were simulated but did not reach comfort category II, these are:

a) no change in the roof, façades with cladding, windows with screen; ventilation shafts

b) roof $2 \mathrm{~cm}$ insulation, façades $2 \mathrm{~cm}$ insulation, windows with screen, ventilation shafts

c) roof $6 \mathrm{~cm}$ insulation, façades $4 \mathrm{~cm}$ insulation, windows with screen, ventilation shafts

The first priority is always to reduce the solar heat transfer through the roof. Without improvements of the roof comfort can't be reached. With a moderate improvement of the roof with $2 \mathrm{~cm}$ thermal insulation it is necessary to block the heat transfer through the façades with a (rear ventilated) cladding or a green façade. Supplemented with a shading of the windows with a screen with $60 \%$ opacity and ventilation shafts comfort can be reached (Table 2, variant A).

Fig. 7 shows the assessment according to EN 15251, the comparison with Fig. 6 shows that now only a few hours of usage (black points) are above the comfort limit, the target is reached with the improvements.

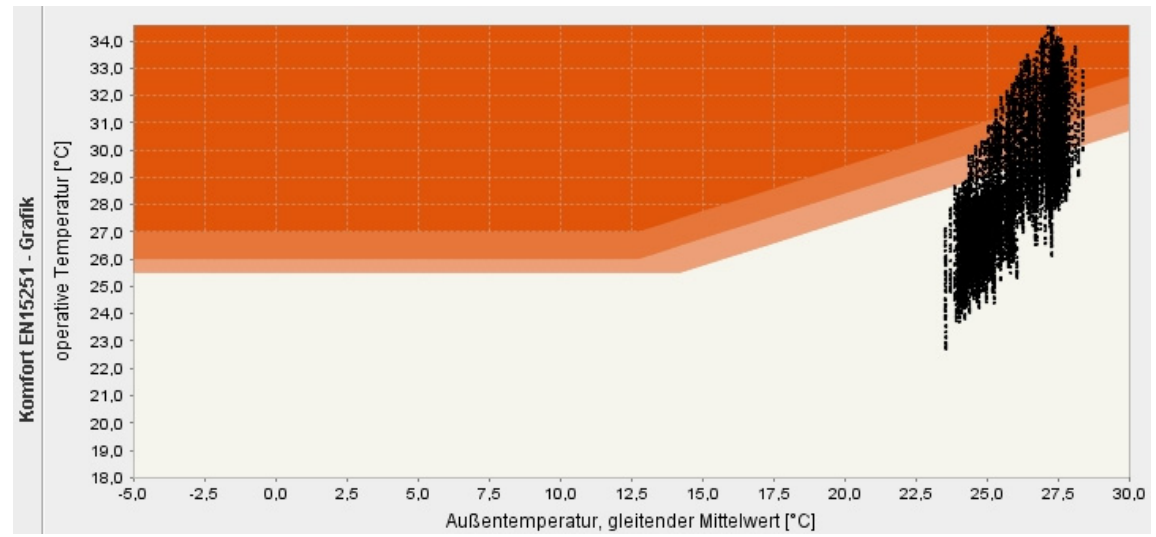

Figure 6: Assessment of contemporary apartment according to EN15251 adaptive comfort model. 
Table 2: $\quad$ Results of successful measures (comfort category II and 3\% of exceedance reached) and their impact on the comfort assessment with adaptive comfort model EN 15251.

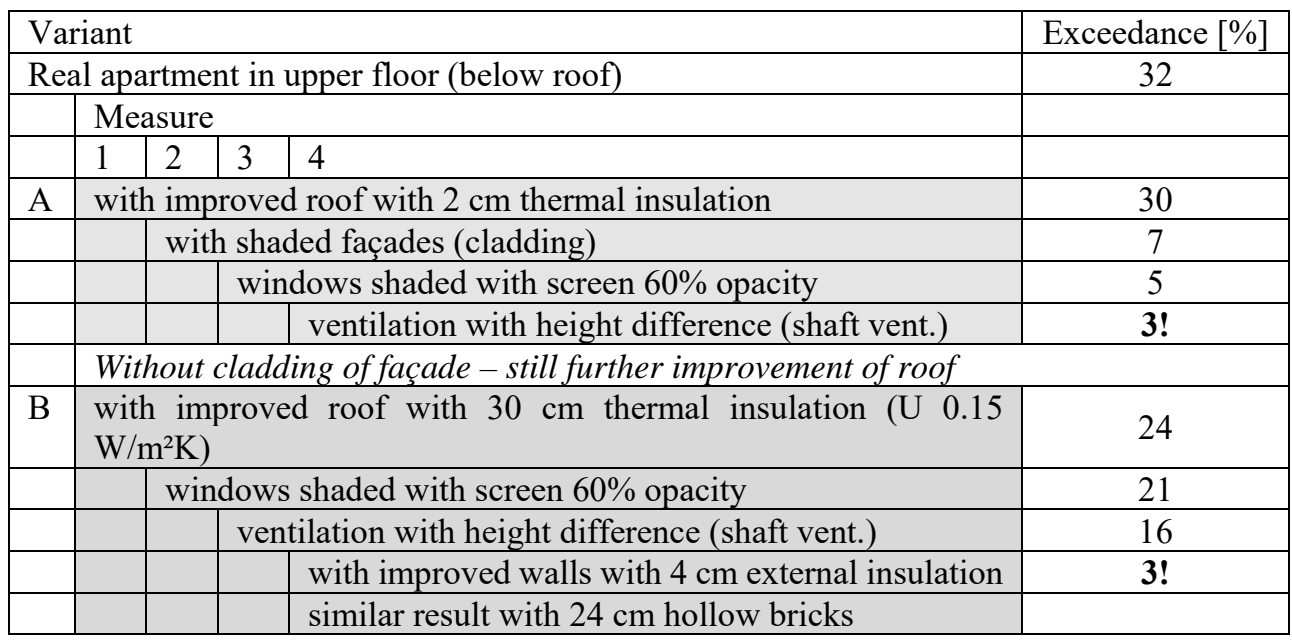

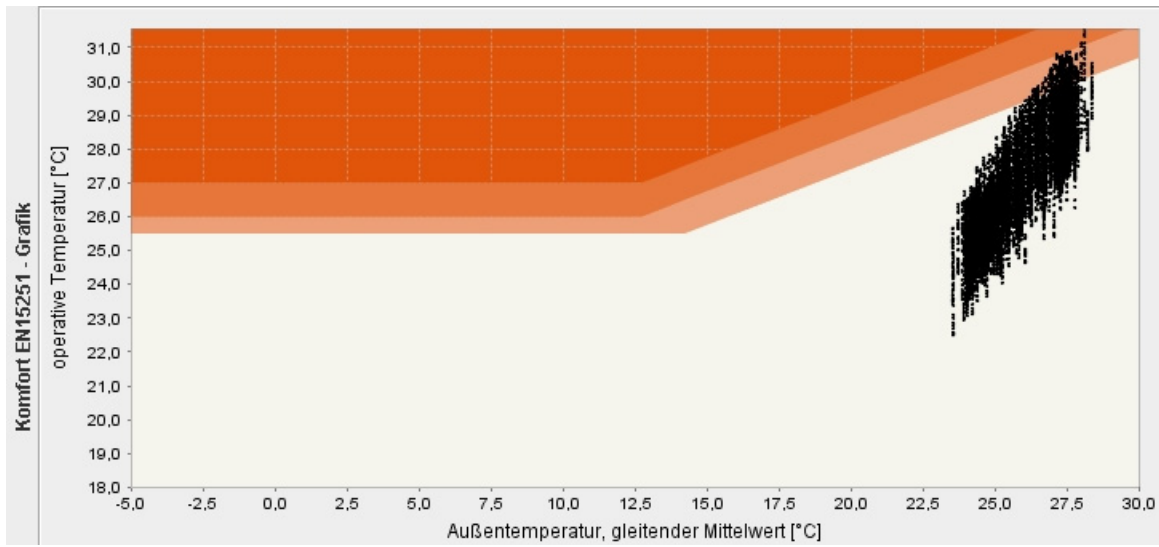

Figure 7: Assessment of improved contemporary apartment according to EN15251 adaptive comfort model.

The red areas show the upper limits of comfort categories I, II and III. The simulated indoor temperature and the corresponding daily mean of the outdoor temperature form one black point for each hour of usage. The graph shows the apartment with improvements that lead finally to comfort category II with $3 \%$ of exceedance. Only very few black points are above the comfort limit.

Further simulations show that a cladding of the façade could be avoided only with an improvement of the roof to a "Passive House" standard of cold climates, $30 \mathrm{~cm}$ insulation. Then comfort could be reached also with shaded windows, shaft ventilation and an improved wall construction (concrete $10 \mathrm{~cm}+4 \mathrm{~cm}$ external insulation) or a different wall construction with $24 \mathrm{~cm}$ hollow bricks (see Table 2, variant B). 
Remarkable is the total decoupling of the last floor under the roof and the outdoor conditions. There is no solar heat transfer through the roof with $30 \mathrm{~cm}$ insulation, the simulation ends with $24 \%$ of exceedance. The same apartment as an intermediate one (see below) and thus any contact to the roof shows with $22 \%$ of exceedance nearly the same value but is of course still far from comfort. The different measures of improvement were simulated. Table 3 shows their impact and if the target of only $3 \%$ of exceedance of comfort category II is reached.

The first priority is also here to reduce the solar heat transfer through the walls, comfort is reached immediately (variant A). But there are also alternatives, comfort could be reached also with shaded windows, shaft ventilation and an improved wall construction (concrete 10 $\mathrm{cm}+4 \mathrm{~cm}$ external insulation) or a different wall construction with $24 \mathrm{~cm}$ hollow bricks or also with the traditional $60 \mathrm{~cm}$ adobe (variant C). Variant B shows an alternative for slightly reduced comfort expectancy. Without supplementary introduction of ventilation shafts and only with shaded windows and improved / different wall construction comfort category III could be reached.

\section{FINAL DISCUSSION}

Simulations confirm that dynamical behaviour of roof and walls is the dominant quantity for that climate. Traditional constructions behave here quite well. But it seems that the corresponding knowledge and consciousness are get lost with the availability of new construction materials (concrete), and comfort could be reached now with appliances in warm weather. The view to "modern" architecture (that comes mostly from colder climates where the dynamical behaviour plays not a dominant role, here the stationary U-value is most important) and separation of investors (that want to construct cheap as possible) and users

Table 3: Summary of different simulated measures (and their combination) and their impact on the comfort assessment with adaptive comfort model EN 15251. The shaded areas in the table show the different possible strategies to reach comfort category II or III resp.

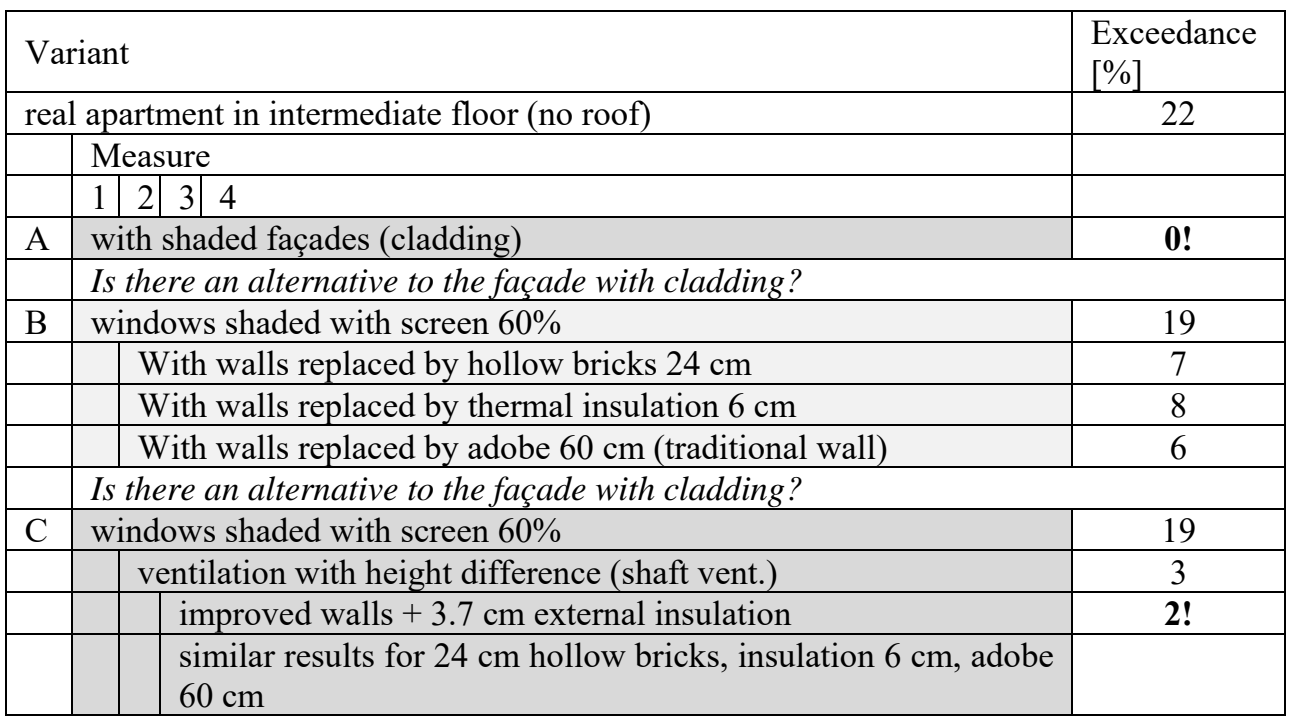


(that do not know about the background and install AC to live in comfort). Also present standards (partly taken from "developed" countries with colder climates) do not request strictly the necessary quantities.

In Brazil, two present standards address the thermal performance of buildings: NBR 15220 [9] and NBR 15575 [10]. NBR 15220 gives recommendations with defined different Brazilian bioclimatic zones to improve the thermal comfort performance in housing, NBR 15575 is the only mandatory standard in this regard. According to NBR 15220 bioclimaticzoning map, Salvador where the buildings were simulated, is located in the zone 8 , for this zone, the standard recommends a permanent cross ventilation, stating in addition that passive design strategies are insufficient in the hottest hours in this bioclimatic zone.

Nevertheless, the simulations confirm comfort is reachable with only passive measures. That shows also the potential and importance for sustainable development. However, to reach comfort the future architecture has to care about protection against solar heat transfer and removal of heat via natural (night) ventilation.

\section{REFERENCES}

[1] 2015 population estimates, Brazilian Institute of Geography and Statistics (IBGE) (PDF). Ibge.gov.br. Retrieved 2015-2011.

[2] EN 15251: Indoor environmental input parameters for design and assessment of energy performance of buildings addressing indoor air quality, thermal environment, lighting and acoustics; 2007. 2008-07 (2007) Criteria for the indoor environment. Beuth Verlag, Berlin.

[3] Sonnenverlauf.de. Online. www.sonnenverlauf.de/\#/-12.973,-38.5023,11/2018.02.05/ 10:53/1/0. Accessed on: 5 Feb. 2018.

[4] EN ISO 13786: Thermal performance of building components-Dynamic thermal characteristics - Calculation methods, 2007.

[5] Online. http://nesa1.uni-siegen.de/mitarb/ehemalige/DissCompaore/Dissertation\%20 Desire\%20Compaore.htm. (German PhD, see chapter 7). Accessed on: 3 Oct. 2017.

[6] Augusto Alvareda, La piel de la arquitectura moderna brasileña, (2013) Universidad politecnica de Cataluña (in Spanish).

[7] Kowaltowski, D.C.C.K., Labaki, L., Gómez, A. \& Pina, S.A.M.G., Verandas en la arquitectura tradicional de Brasil Doris Universidad de Colima, 2015 (in Spanish).

[8] Primero-Comfort. Online. www.primerosoftware.de. Accessed on: 14 Jan. 2017.

[9] ABNT, NBR 15.220: Desempenho térmico de edificações. Rio de Janeiro, Brazil: Brazilian Association of Technical Standards, 2005 (in Portuguese).

[10] ABNT, NBR 15.575: Edifícios habitacionais-Desempenho. Rio de Janeiro, Brazil: Brazilian Association of Technical Standards, 2013 (in Portuguese). 